\title{
Predicting migration routes for three species of migratory bats using species distribution models
}

\author{
Jamin G Wieringa ${ }^{\text {Corresp., 1, }}{ }^{2}$, Bryan C Carstens ${ }^{1}$, H Lisle Gibbs $^{1,2}$ \\ ${ }^{1}$ Department of Evolution, Ecology and Organismal Biology, The Ohio State University, Columbus, OH, United States \\ 2 Ohio Biodiversity Conservation Partnership, The Ohio State University, Columbus, $\mathrm{OH}$, United States \\ Corresponding Author: Jamin G Wieringa \\ Email address: wieringa.3@osu.edu
}

Understanding seasonal variation in the distribution and movement patterns of migratory species is essential to monitoring and conservation efforts. While there are many species of migratory bats in North America, little is known about their seasonal movements. In terms of conservation, this is important because the bat fatalities from wind energy turbines are significant and may fluctuate seasonally. Here we describe seasonally resolved distributions for the three species that are most impacted by wind farms (Lasiurus borealis [eastern red bat], L. cinereus [hoary bat], and Lasionycteris noctivagans [silverhaired bat]) and use these distributions to infer their most likely migratory pathways. To accomplish this, we collected 2880 occurrence points from the Global Biodiversity Information Facility over five decades in North America to model species distributions on a seasonal basis and used an ensemble approach for modeling distributions. This dataset included 1,129 data points for L. borealis, 917 for L. cinereus, and 834 for L. noctivagans. The results suggest that all three species exhibit variation in distributions from north to south depending on season, with each species showing potential migratory pathways during the fall migration that follow linear features. Finally, we describe proposed migratory pathways for these three species that can be used to identify stop-over sites, assess small-scale migration and highlight areas that should be prioritized for actions to reduce the effects of wind farm mortality. 
1 Predicting migration routes for three species of migratory bats using species distribution models

3 Jamin G. Wieringa*1,2 ${ }^{*}$ Bryan C. Carstens ${ }^{1}$, and H. Lisle Gibbs ${ }^{1,2}$

4 Affiliations: 1. Department of Evolution, Ecology and Organismal Biology, 300 Aronoff Lab,

5318 W. 12 $2^{\text {th }}$ Ave., The Ohio State University, Columbus, OH, USA 2. Ohio Biodiversity

6 Conservation Partnership, Oho State University, Columbus, OH, USA

7 *corresponding author: wieringa.3@,osu.edu 


\section{Abstract}

Understanding seasonal variation in the distribution and movement patterns of migratory species is essential to monitoring and conservation efforts. While there are many species of migratory bats in North America, little is known about their seasonal movements. In terms of conservation, this is important because the bat fatalities from wind energy turbines are significant and may fluctuate seasonally. Here we describe seasonally resolved distributions for the three species that are most impacted by wind farms (Lasiurus borealis [eastern red bat], L. cinereus [hoary bat], and Lasionycteris noctivagans [silver-haired bat]) and use these distributions to infer their most likely migratory pathways. To accomplish this, we collected 2880 occurrence points from the Global Biodiversity Information Facility over five decades in North America to model species distributions on a seasonal basis and used an ensemble approach for modeling distributions. This dataset included 1,129 data points for L. borealis, 917 for L. cinereus, and 834 for $L$. noctivagans. The results suggest that all three species exhibit variation in distributions from north to south depending on season, with each species showing potential migratory pathways during the fall migration that follow linear features. Finally, we describe proposed migratory pathways for these three species that can be used to identify stop-over sites, assess small-scale migration and highlight areas that should be prioritized for actions to reduce the effects of wind farm mortality.

Keywords: bats, GBIF, Lasiurus borealis, Lasiurus cinereus, Lasionycteris noctivagans, migration pathway, species distribution models 


\section{Introduction}

Conservation and management of migratory animals requires knowledge about their seasonal movements across space and time (Webster et al. 2002). In a wide variety of taxa, species migrate when resources vary seasonally (Shaw \& Couzin 2013) or temperature variation results in thermal stress (Fleming \& Eby 2003). Due to small body sizes it is difficult to track long distance movements of many taxa such as species of bats, birds, and insects reducing our understanding of their migratory behavior. While some progress has been made using light-level geolocators (Åkesson et al. 2012) and various biomarkers (e.g., Hobson \& Wassner 2018), these methods have limitations such as requiring recapture and low precision, respectively and as a result are limited in their impact. This is particularly true for bats, small-bodied nocturnal mammals capable of true flight.

Although many species of bats migrate, only 12 of 500 Vespertilionid bats undertake long-distance migration and understanding their migration is vital to the conservation of these species (Fleming \& Eby 2003; Simmons \& Cirranello 2020; Welbergen et al. 2020). By understanding the migration of these species, we can better understand the pressures an individual will face during migration or at home ranges during non-migratory time periods. However, limited information is currently available about the long-distance migration of bats in North America. For example, in most species the approximate direction (north-south), time of year, and some rough estimates of distances travelled are all that is known (Fleming \& Eby 2003; Pettit \& O'Keefe 2019) with much of this information inferred from distribution modeling in these species (e.g., Hayes, Cryan \& Wunder 2015) or biomarker studies, such as isotopes (e.g., Cryan, Stricker \& Wunder 2014). 
54

of North American tree bats. For example, Baerwald, Patterson \& Barclay (2014) used isotope information to propose that Lasiurus cinereus and Lasionycteris noctivagans use the eastern slopes of the Rocky Mountains as a migration route. Further, Cryan, Stricker \& Wunder (2014) used stable isotope data to suggest that L. cinereus has some east-west movement during migration in addition to the north-south, likely toward coastal regions during Autumn migration that potentially contain more suitable winter habitat.

In contrast to our understanding of migration in North American bats, there is more known about bats from Europe and other regions. Previous studies have shown repeated and partial migration (Lehnert et al. 2018), and that bats showed site fidelity at stop-over sites during migration (Giavi et al. 2014). One important aspect of research is understanding how bats navigate during migration and some have suggested the tracking of linear features for bat migration (e.g., Voigt et al. 2016; Ahlén et al. 2009), although others have challenged this interpretation (Krauel et al. 2018). Further studies have also shown the impacts of humans during migration. Human activities have the potential to disrupt bat migration via mechanisms such as interfering with magnetic navigation (Voigt et al. 2017), increasing light pollution (Lacoeuilhe et al. 2014), developing wind farms along migration corridors (Hayes, Cryan, \& Wunder 2015), or reducing stop-over sites and food availability through deforestation and habitat destruction. To mitigate these effects, a better understanding of migration in bats is needed.

A few of these species such as L. borealis (Eastern Red bat), L. cinereus (Hoary bat), and L. noctivagans (Silver-haired bat) have been a focus of understanding these behaviors in North America due to their high mortality at wind farms, with some estimates predicting a $90 \%$ species population decline within 50 years due to wind farm interactions (Frick et al. 2017). Bats are the 
most common animal found dead beneath wind turbines in North America (Kunz et al. 2007) with the majority $(\sim 80 \%)$ of these individuals consisting of just the three species of migratory listed above (Arnett \& Baerwald 2013). Most of the fatalities for these species occur during a period of time coinciding with autumn migration (Kunz et al. 2007), but data linking the act of migration and mortality is lacking. Overall, a more precise delineation of possible migratory corridors (defined here as the most likely path followed during migration) and how these influence wind farm interactions could help to minimize impacts of wind facilities on these species.

One explanation for the uncertainty about long-distance migratory pathways of migratory bats is the lack of data on spatial locations through time which is in contrast to such data which are widely available in better-studied migratory species such as birds. One reason for this difference is that observational data on birds can come from a variety of Citizen Science initiatives such as the Breeding Bird and Christmas Bird Surveys and eBird (National Audubon Society 2010; Sullivan et al. 2009). The difference in data quantity is large. For example, a common migratory bird, the yellow warbler (Setophaga petechia) has 2.39 million occurrences the Global Biodiversity Information Facility (GBIF; checked 11 Dec 2019) whereas the entire family of Vespertilionidae bats consisting of $>400$ species have only 1.49 million occurrences recorded. While the causes of this disparity are many, the difference highlights the need to use other sources of data for to study broad scale patterns of bat migration.

One approach to better understand seasonal distributions and identify migratory corridors is to generate seasonally explicit species distribution models (SDMs; Fink et al. 2010, Hayes, Cryan, \& Wunder 2015; Smeraldo et al. 2018) and use these to infer movement patterns. This approach has been successful in other migratory species, such as birds (Reynolds et al. 2017). 
99 While other studies have begun to explore this approach with tree bats (see Findley \& Jones

100 1964; Cryan 2003; Hayes, Cryan, \& Wunder 2015), much of this work has focused on overall

101 distributions as opposed to seasonal differences in movement. However, seasonal movements

102 can be studied by generating models of bat distributions on a month-by-month basis that allow

103 seasonal variation to be visualized and infer the movement that took place between monthly

104 occurrences.

In this study, our objective was to identify possible migratory pathways utilized by

migratory bat species in North America (L. borealis, L. cinereus, and L. noctivagans) through

modelling their seasonal distributions using SDMs. While not the first study to generate SDMs

for these species, it is the first to use them to infer migration patterns for the time between

seasonal occurrences. The models generated in this study shed light on the seasonal dynamics for

these three species and highlight areas of interest for further study of migratory corridors that

111 could be used to investigate stop-over sites, small scale migration, and be used as a starting point

for designing methods to mitigate wind farm mortality.

\section{Methods}

Occurrence data from GBIF

115

116

117

118

119

120
Figure 1 shows an overview of the steps involved in data collection and analysis; more detailed methods are described on Supplemental Material. To begin, all available occurrence data were downloaded for L. borealis, L. cinereus, and L. noctivagans through the GBIF data portal (http://www.gbif.org) on 11 March 2019 using only 'Preserved Specimens', 'Human Observations', and 'Material Sample' keywords for data from the past 50 years (https://doi.org/10.15468/dl.dpiwzi, https://doi.org/10.15468/dl.irfol0, and 
121 https://doi.org/10.15468/dl.viiyt5, respectively). This 50-year period was selected because it

122 allows for more confidence in the call of a species and its locality. While some previous studies

123 have verified occurrence data from older than 50 years ago (see Hayes et al. 2015), we were

124 unable to access the data from the museum collections used in that study. In addition, due to

125 climate change ranges may be shifting as has been observed in some mammal species (MacLeod

126 2009) and so using more recent occurrence data likely provides more accurate current ranges. All

127 downloaded records were screened using several filters (described below) as recommended by

128 others (Feeley \& Silman 2011; Carstens et al. 2018). Once data sets were filtered using these

129 criteria, we corrected for over sampling within a $1^{\circ}$ region following guidelines given by

130 Hijmans and Elith (2017). In brief, we created a grid of $1^{\circ}$ resolution $(\sim 111 \mathrm{~km})$ and subsampled

131 our occurrence data to one occurrence per grid cell. This was done to reduce the possibility of

132 sampling bias in our data. While there exists a possibility of overthinning data, a larger concern

133 was sampling bias inflating suitability of certain regions especially on these analyses as

134 suitability will determine the inferred pathways. This is especially true for the known spatial bias

135 that exists in GBIF data, due to differences in funding and data sharing of institutions (Razgour

136 et al. 2016). As a result, we took the conservative approach of $1^{\circ}$ grid sampling. In addition,

137 other continent-wide studies for some species have used similar scales for filtering and were

138 shown to be an effective filtering approach (Fourcade et al. 2014). Lastly, some have suggested

139 that sampling be limited to an approximate home range for a species (Kramer-Schadt et al.

140 2013). In this case, due to the highly volant nature of bats with the ability to travel long distances

141 of a given night broader filtering is needed. For example, Morningstar and Sandilands (2019)

142 documented an individual $L$. cinereus traveling over $800 \mathrm{~km}$ in two weeks, finishing $\sim 50 \mathrm{~km}$ from 
143 the initial roost. As a result of this high mobility, a larger grid sample likely produces more

144 accurate distribution models.

145 Predictor environmental variables

146 WorldClim version 2 monthly climatic data were used at 2.5-minute resolution ( $4.5 \mathrm{~km}$; Fick \&

147 Hijmans 2017) for our species distribution models and included the following variables:

148 precipitation $(\mathrm{mm})$, solar radiation $\left(\mathrm{kJ} \mathrm{m}^{-2}\right.$ day $\left.^{-1}\right)$, average temperature $\left({ }^{\circ} \mathrm{C}\right)$, maximum

149 temperature $\left({ }^{\circ} \mathrm{C}\right)$, minimum temperature $\left({ }^{\circ} \mathrm{C}\right)$, vapor pressure $(\mathrm{kPa})$, and wind speed $\left(\mathrm{m} \mathrm{s}^{-1}\right.$;

150 downloaded on 03 June 2019 from worldclim.org). WorldClim is a database of high spatial

151 resolution global weather and climate data. These data can be used for mapping and spatial

152 modeling. Additionally, elevation maps (Tachikawa et al. 2011; 11 March 2019), and the human

153 influence index (CIESIN, 2005; 11 March 2019) for North America were also downloaded as

154 Jung and Threlfall (2016) showed a negative response to urbanization in the Americas in

155 insectivorous bats in the family Vespertilionidae. Human influence was determined by

156 combining population density, human land use and infrastructure, and human access (WCS,

157 2005). Following Hayes et al. (2015), we also included MODIS Normalized Difference

158 Vegetative Index (Didan et al. 2015) and Global Tree Coverage 2010 (Hansen et al. 2013) as

159 metrics of seasonality and leaf growth, which could impact prey abundance, and be a metric of

160 available roost sites in trees, downloaded on 04 June 2019 and 05 June 2019, respectively. Prior

161 to final selection of predictor variables, correlations between each possible pair of predictor

162 variables were determined and one variable from each pair that was strongly correlated with the

163 other was removed ( $\mathrm{r}>0.8$; Mateo et al. 2013). Any removal of a variable was determined based

164 on biological relevance and previous uses in literature.

165 Species distribution modeling

Peer) reviewing PDF | (2020:12:56189:1:0:NEW 16 Feb 2021) 
166 Species distribution models were generated for each species using five different methods: four

167 specific model algorithms and an ensemble approach (see below). Specific algorithms included:

168 generalized linear model (GLM; Guisan, Edwards, \& Hastie 2002), BIOCLIM model (BC;

169 Booth et al. 2014), random forest (RF; Breiman 2001; Mi et al. 2017), and maximum entropy

170 (MaxEnt; Phillips, Dudik, \& Schapire 2017). These four approaches, while good predictors

171 individually, can be made more effective through an ensemble method. This approach accounts

172 for the problems of each model and can allow for better performing models (Araújo \& New,

173 2006; Marmion et al. 2009) and is becoming more common (Razgour et al. 2016). Due to this

174 and our results (see below), we used the ensemble models for all analyses.

All SDM analyses were carried out in R using the packages "randomForest" (Liaw \&

176 Wiener 2018), "raster" (Hijmans et al., 2019), "rgeos" (Bivand et al. 2019), "maptools” (Bivand

177 et al. 2019), “dismo” (Hijmans et al. 2017), “sp” (Pebesma, Bivand, \& Pebesm, 2012),

178 “ecospat" (Di Cola et al. 2016), and "rJava" (Urbanek 2019). We created 1000 pseudo absence

179 points for each month from random points in the background layers and partitioned the model

180 into testing (80\%) and training data (20\%) using the "kfold" function.

Each model was then assessed using the Area under the ROC (receiver operating characteristic) curve (AUC) and the True Skill Statistic (TSS). These values were then used to weigh each layer and were then combined into a single ensemble SDM. Following generation of our ensemble models, they were assessed using the same AUC and TSS metrics as outlined above and data points used for all other models for comparison to determine which model to use for further analysis. These layers were then used to predict migratory pathways. model. For RF we used the 'importance' function in the "randomForest" R package to measure 
189 the importance of a variable in a model. With MaxEnt, variable importance was assessed using

190 'var.importance' function in "ENMeval" to determine the importance of each variable

191 (Muscarella et al., 2014). For the GLM model, we used the 'varImp' function present in "caret"

192 (Kuhn et al., 2020).

193 Migratory pathways

194 To identify migratory pathways using SDMs we used three complementary methods: circuit

195 theory (McRae \& Beier 2007; Shah \& McRae 2008), 95 ${ }^{\text {th }}$ percentile suitability (Poor et al. 2012),

196 and least cost path analyses (LCP; Howey 2011). Since each of these methods have advantages

197 and disadvantages, results from these three methods were compared to generate a consensus

198 delineation of possible corridors (Bond et al. 2017; Marrotte \& Bowman 2017). While some

199 authors have argued for selecting the single best hypothesized approach (Marrotte \& Bowman

200 2017), as we do not know if these species follow linear features as has been observed in some

201 species (Ahlén et al. 2009) or exhibit more erratic movements, we could not confidently select a

202 single approach. Multiple authors (Dutta et al. 2015; Medley, Jenkins \& Hoffman 2015) show

203 that circuit and least-cost based analyses complement each other and can give more insight into

204 the movement of a species. In addition, the use of circuit theory and least-cost-path allow for

205 some movement through less suitable areas. In least-cost-path analyses an individual's path may

206 go through less suitable areas as the model weighs both distance and suitability of the areas

207 traveled through. For example, the model would give preference for travel through a single less

208 suitable cell if the cumulative cost is less than four more suitable cells. Similarly, in circuit

209 theory it is possible for the "current" (an individual movement likelihood) to pass through less

210 suitable cells as long as the total resistance to do so is less than adjacent alternative paths. 

aggregated our winter month occurrences (December - February) into a single dataset and did the same for summer months (June-July), using Hayes et al., (2015) to determine the appropriate months for each season. As SDMs can be interpreted as conductance maps, we used an average of both spring and fall months (March, April, May; and August, September, October, respectively) to assess potential corridors between winter and summer occurrences. These time periods are based on previously published distributions of occurrences (Cryan 2003), previous SDM modeling (Hayes, Cryan, \& Wunder 2015), wind farm fatality data (Arnett et al. 2008), radio telemetry (Walters et al. 2006), and acoustic data (Muthersbaugh et al. 2019). Using Circuitscape (Shah \& McRae 2008), we set our start ("source") and end ("ground") points based on the hypothesized direction of migration. To identify patterns of spring migration, we set our start as winter occurrences and end as summer points, with the spring SDMs as the conductance raster; and summer as start and winter as end with fall SDMs as the fall migration conductance raster; this was repeated for each species. 'shortestPath' implemented in 'gdistance' (Van Etten 2017). The analysis was done iteratively between all points previously designated as "Winter" and "Summer" points for Circuitscape, and spring/fall conductance surfaces for cost determination. As single pathways are likely not informative for species-wide migratory pathways, we combined each least cost path to create a density of pathways. A high density of overlapping paths was used to identify a potential migratory pathway. Additionally, while we are unable to infer if a proposed path is true, we used

232 Moran's I (Moran 1950) and Geary's C (Geary 1954) to quantify if these proposed pathways are 233 positively clustered, as would be expected in a migratory corridor. We also quantified the 
234 distance traveled compared to straight-line distance to determine if the proposed pathways would

235 be biologically relevant (i.e., if not following straight line, other factors influence where bats

236 migrate through). Next, binary rasters identifying potential migratory pathways using the $95^{\text {th }}$

237 percentile approach was generated to identify areas where bats are more likely to be concentrated

238 compared to background (Poor et al. 2012). This was to identify areas where suitability is higher

239 and therefore a potential migratory pathway. Finally, overlaps between Circuitscape, least cost

240 path, and $95^{\text {th }}$ percentile approaches were identified to highlight locations where they agreed and

241 those were inferred to be potential migratory pathways.

242

To ensure we are tracking migration and not simply sampling bias, a comparison between

the results for migratory pathways above and those from two non-long-distance migratory species (Myotis lucifugus and Eptesicus fuscus) following the same methods above was carried out. If the pathways are similar to those from these two species it is possible that we are tracking the ability to capture bats during the winter instead of actual movement. On the other hand, if pathways are different, then it is more likely that we are identifying true pathways. Occurrence data for these additional species were collected from GBIF on 31 January 2020 (https://doi.org/10.15468/dl.fphagx) and were treated in the same manner as the three migratory

250 species to generate SDMs and test migratory pathways.

\section{Results}

253 A total of 20,697 occurrences were downloaded from the GBIF database: 8,362 for L. borealis, 2547,649 for L. cinereus, and 4,686 for L. noctivagans. After filtering, there were 10,743 data points 255 remaining: 4,380 for L. borealis, 3,736 for L. cinereus, and 2,627 for L. noctivagans. Finally, 
256 after accounting for sampling bias there were 1,129 data points for L. borealis, 917 for $L$.

257 cinereus, and 834 for L. noctivagans (Figure 2). For each month numbers of data points ranged

258 between 21 and 205 (Table 1). All months were above the minimum of 13 observations

259 suggested by van Proosdij et al. (2016) (based on simulated data) as necessary for SDM analyses

260 for wide ranging species. Further, only December for two species had occurrences below a

261 higher secondary minimum threshold of 25 data points based on empirical data (per van Proosdij

262 et al. 2016). SDM analyses were conducted with each subset of data using each of the 5

263 modeling approaches: GLM, BC, RF, MaxEnt, and ensemble, for a total of 60 model runs for

264 each species. While we acknowledge the presence of other datasets (see NABat

265 [https://www.nabatmonitoring.org/] and/or American Wind/Wildlife Institute [https://awwi.org/]),

266 we found that we had sufficient data available via GBIF for all months given that we had over

26725 occurrences for 11 months, and the only month below this threshold is also deficient in other

268 datasets. Further these other datasets are not comprehensive across North American for all

269 months and/or are not readily available to the public.

\section{Predictor variables}

271 Following removal of variables that were highly correlated $(r>0.8)$, eight variables were retained:

272 elevation, forest coverage, NDVI, precipitation, solar radiation, average temperature, vapor

273 pressure and wind speed. The variables that were removed were minimum and maximum

274 temperature which were highly correlated with average temperature $(\mathrm{r}=0.98$ and 0.99 ,

275 respectively). Average temperature was selected due to the ability of bats to regulate their body

276 temperature and energy expenditure through torpor (Baloun \& Guglielmo 2019). While relative

277 importance of variables fluctuated between the four original models implemented (GLM,

278 MaxEnt, RF, and BC), in general, average temperature, solar radiation, and vapor pressure were 
279 the most important variables (Table 2; specific weights Table S1). In contrast, NDVI, percent

280 forest, wind, and precipitation were consistently the least important variables.

281 Species distribution models

282 AUC scores range from 0.50 to 0.99 , while TSS values range from 0.44 to 0.95 across all 5 types

283 of models. When evaluated by both AUC and TSS, the consistently best performing species

284 distribution model was the TSS weighted ensemble model (Figure S1), with this model having a

285 minimum AUC of 0.94 and TSS of 0.78 (Table S2), indicating a high predictive performance

286 (e.g. Smeraldo et al., 2018). In addition, these high values indicate sufficient sampling (both

287 number and spatial scale) present for the analyses completed. With the exception of the model

288 for L. borealis for July, our TSS weighted ensemble model was always determined to be the best

289 model by both AUC and TSS. As a result of the ensemble models consistently high performance,

290 it was used for all subsequent analyses. We now describe the results for each of the three species.

While we did not explicitly explore the seasonal variation present in each species

292

293

294

295

296

297

298

299

300

generated SDM's, this variation can be observed in Figure 3 (each species detailed in Figure S2-

4). In short, we observe trends that are similar to those found in previous studies (e.g. Baerwald

\& Barclay 2011; Johnson et al. 2011; Hayes, Cryan, \& Wunder 2015). For L. borealis and L.

cinereus we observe concentration of habitat suitability in the southern portions of their range

during winter months with a northward movement during the summer into early fall. This is

followed by a contraction again to the south. On the other hand, L. noctivagans exhibits a different pattern: while it has suitable habitat further north during the winter and expands northward it doesn't appear to do so to the same extent as the other two species. With these results being similar to expected, we can use them to predict the most likely migratory pathways. 
301

302

303

304

305

306

307

308

309

310

311

312

313

314

315

316

317

318

319

320

321

322

323

\section{Potential migratory pathways}

Using three methods (Circuitscape, LCP, and $95^{\text {th }}$ percentile), we find potential migratory pathways for each species that vary between the spring and fall seasons (Figure 4; Circuitscape maps are shown in Figure S5). In terms of spring migration patterns, L. borealis shows highest density of LCP along the Eastern coast of the U.S. and near the Mississippi River suggesting an avoidance of the Appalachian Mountains and using coasts and rivers as guidance during migration (Figure 4). This pattern is also present in the $95^{\text {th }}$ percentile maps. For L. cinereus, higher LCP densities occur along Western Mexico into the Southern U.S., after which the higher probability pathways lie on either side of the Rocky Mountains pattern and along the Atlantic coast suggesting a lack of resolved pathway during this time period (Figure 4). This is also supported by the $95^{\text {th }}$ percentile map showing higher suitability scores being present in both these regions before the paths would extend further north. Finally, L. noctivagans shows two different patterns: LCP maps suggest movement from south to north in the Western U.S. along the Pacific coast and along the western edge of the Rocky Mountains (Figure 4). In the Eastern U.S. there appears to be more of an east-west movement during which individuals would split off to move north or south, likely indicating a partial or incomplete migration in this species. For each of these species we see significant positive clustering in our pathways when using both Moran's I and Geary's C (Table 3). We can also observe that these potential pathways are significantly longer than straight line distance by hundreds of kilometers meaning these pathways would be biologically important, or in other words, that the most likely paths found here follow some biologic aspect of the area.

In terms of fall patterns, $L$. borealis shows two apparent migration paths: one along the East coast, and the other near the Mississippi River and into the Southern plains (Figure 4). 
324 These paths are supported by the $95^{\text {th }}$ percentile map, which shows suitable habitat in these areas

325 at the same time of year. These two paths again indicate a potential following of coastline and

326 rivers as linear guides during migration. L. cinereus shows evidence for multiple pathways

327 (Figure 4). Two possible pathways are present along the coasts of the Atlantic and Pacific, again

328 indicating a possible following of coastlines during migration. While the Pacific is the clearer

329 pathway of the two there is still a high density of lines along the Atlantic, which could be a

330 minor pathway for those individuals navigating around the Appalachian Mountains. In addition,

331 a pathway appears in our LCP map and is supported by the $95^{\text {th }}$ percentile map along the

332 Mississippi River. There is also evidence for movement through the Great Plains between the

333 eastern slopes of the Rocky Mountains and the interior highlands near Missouri and Arkansas.

334 Finally, L. noctivagans shows similar patterns for fall as those observed during spring migration

335 periods (Figure 4). We see a north-south pathway west of the Rocky Mountains, and east of

336 those, a more east-west pathway is observed, with movements extending north or south, which

337 again potentially indicates a partial or incomplete migration. With fall migration, we also

338 observe positively clustered pathways that are significantly longer than Euclidean distance

339 (Table 3).

The two bats that are not long-distance migrants show less variation in seasonal

distribution as compared to the three migrant species discussed earlier (Figure 4). In particular,

both E. fuscus and M. lucifugus show a consistent east-west distribution pattern that does not

343 change throughout the year. This supports the idea that changes in distributions of the migratory

344 species likely reflect migratory behavior. Of interest is that the pathways determined by LCP for

345 E. fuscus are similar to L. noctivagans, providing additional support that silver-haired bats

346 undergo only a partial migration, that being some individual migrant while others overwinter in 
347 northern portions of the range. This seems possible as it has been documented silver-haired bats

348 can overwinter at Northern latitudes (Cryan, 2003).

\section{Discussion}

350 Other studies have used SDMs and occurrence to model seasonal distributions of wide-ranging

351 migratory bats including those studied here (e.g., Cryan 2003; Hayes, Cryan, \& Wunder 2015).

352 This study extends this approach by using SDMs to predict migratory corridors, in this case the

353 most likely path used. In essence, while others have used these data to delineate where bats are at

354 a given time, we expand on this by attempting to understand what is happening between these

355 occurrences. Below we discuss limitations of our analyses and then expand on the conservation

356 implications of our results.

\section{Analysis limitations}

358 Using species occurrence data to generate species distribution models can be impacted by

359 sampling biases present in the data (Feng et al. 2019). We attempted to minimize these biases by

360 following guidelines described in Feng et al. (2019). Specifically, we took steps to reduce

361 oversampling of regions by subsampling our dataset to 1 point per $1^{\circ}$ grid cell. Additionally,

362 because occurrence records only represent presence points, and not true absences, we included

363 models that require only presence data or can be adapted for use with presence only data. Despite

364 these measures, it is possible biases remain in our models and so we stress that our models

365 represent hypothetical species distributions and migratory pathways for any point in time.

366 Another potential limitation with this approach is ability of bats to traverse unsuitable habitat.

367 This could lead to some true pathways we are unable to predict as our models "prefer" suitable

368 areas for inferring patterns of movement. However, the approaches used allow for some level of 
369 traversing areas of unsuitable habitat prior to using suitable stop-over sites (as noted above). As a

370 result, we further stress that the pathways presented are only the most likely to be used and

371 should be investigated further via other sources of data for inferring individual movements such

372 as biomarkers and GPS tags.

\section{Migratory Pathways}

374 Our analyses identify potential migratory pathways across modelling approaches, although we

375 observed some differences that likely result from features of the data that are given different

376 weight by different methods (McClure, Hansen, \& Inman 2016). For example, we were unable to

377 identify clear pathways using Circuitscape despite using multiple transformations of our data

378 (square root, log, natural $\log$, and cube-root transformations). The lack of identifiable paths using

379 Circuitscape may indicate a true lack of clear migratory pathways yet still reflect the general

380 patterns shown by the other methods. This is supported by the least cost path analysis, as while

381 the figures present the most likely paths (Figure 4), many other paths were evident (see Figure

382 S6). Diffusion or a wandering migration, across the landscape has been proposed for these

383 species in previous studies (Weller et al. 2016; McGuire 2019). As noted in Baerwald et al.

384 (2021) for some species of migratory bats, more erratic 'wandering' movements in opposite

385 direction of typical seasonal movements may be observed. While we find some evidence for this

386 in our data, the Circuitscape maps identity areas of higher possible movement are also predicted

387 by the LCP and $95^{\text {th }}$ percentile threshold methods, providing support for specific proposed

388 pathways. We emphasize that our results are not definitive delineations of a single migratory

389 corridor followed by all individuals for the entire duration of migration. Rather, they identify the

390 general paths followed during spring and fall migration while allowing for individual variation. 
We note that specific features of our most likely migration pathways match patterns

392

393

394

395

396

397

398

399

400

401

402

403

404

405

406

407

408

409

410

411

412

413

proposed by others. For example, in L. cinereus we find support movement along the eastern

slope of the Rocky Mountains. The same pattern was proposed by Baerwald, Paterson \& Barclay

(2014) as a likely route followed by spring and fall migrants of the same species to and from

Alberta, Canada based on isotope data. In addition, consistent with our study, results from GPS

tagging work suggest that L. cinereus uses the west of the Rocky Mountains during Autumn

migration (Weller et al. 2016), although the sample size was limited. Finally, further work in $L$.

cinereus using isotopes by provides strong support for predominantly north-south movement

(especially in the Autumn) with some east-west movement (Cryan, Stricker \& Wunder (2014).

These patterns are also observed in our data.

In addition, while some differences between this study and those observed in Cryan,

Stricker \& Wunder (2014) such as apparent crossing of the Rocky Mountains, these could be in part due to how the pathways are presented. In Cryan, Stricker \& Wunder (2014) they represent movement using straight lines, whereas in nature bats may follow less direct, linear paths which are better captured by our approach. Further differences can be observed for L. cinereus in that Cryan, Stricker \& Wunder (2014) find less support for north-south movement during spring than we do. This difference could be an artifact of the use of isotope data which can lack precision, or it's possible our current understanding of spring migration is different than previously expected and tested here. Weller et al. (2016) also found some differences between our proposed pathways and their data. While their sample sizes were limited, they found some support for a more 'wandering' migration in this species (at least west of the Rocky Mountains).

Finally, in L. borealis, there have been numerous reports of individuals being captured offshore during migratory time periods (e.g., Sjollema et al. 2014; Hatch et al. 2013). These 
414 reports support our findings suggesting bats use linear features, such as coastlines, during

415 migration. Lastly, L. noctivagans is regularly captured during winter months in the northern

416 portions of their range (Falxa 2007; Barnhart \& Gillam 2017) supporting the interpretation of

417 this species as a partial migrant. However, as noted in Baerwald, Paterson \& Barclay (2014),

418 some individuals are likely migratory and may follow some portion of the Rocky Mountains, a

419 path not strongly supported in our data for L. noctivagans. The lack of clear pathways for $L$.

420 noctivagans also support the 'wandering' migration proposed by McGuire (2018). In summary,

421 while some differences do exist between our results and others, the broader trends in terms of

422 patterns of movements in these bats appear to be mostly consistent with previous studies.

The most likely pathways found here for bats match migratory patterns of many other

424 species in North America including waterfowl and insects (e.g., Lincoln 1935; Westbrook et al.

425 2016; Tracy et al. 2019). Of interest is the similarity to insect migrations which is consistent with

426 an idea proposed by Rydell et al. (2010) that bat deaths at wind farms may be related to feeding

427 on migratory insects near turbines. Bats may be tracking the migration of insects to determine

428 their pathways and are feeding on them during migration leading to turbine mortality of bats (but

429 see Reimer, Baerwald, \& Barclay 2018).

430 Another possible explanation for the paths in the results are that bats use linear features,

431 such as rivers, coastlines, and mountain ranges, as guides during migration (Wang et al. 2007;

432 Ijäs et al. 2017). For example, in L. borealis we observe apparent tracking of the Mississippi

433 river and Atlantic Coast/eastern edge of Appalachian Mountains, while L. cinereus tracks the

434 previous two mentioned and the Pacific Coast. One proposed rationale for the tracking of water

435 bodies is that these features support a higher abundance of prey to feed upon during migration,

436 allowing for more rapid travel (Furmankiewicz \& Kucharska 2009). We note, however, that 
437 other studies have failed to support this idea. For example, Krauel, McGuire \& Boyles (2017) did

438 not find evidence that another species of bat (Myotis sodalis) used rivers as a navigation guide

439 during migration. Likewise, based on data from acoustic surveys, Cortes and Gillam (2020) did

440 not find support for the use of the Missouri River as a migration guide for multiple species.

441 These differences may be due to the geographic scale at which the studies were conducted

442 compared to the results presented here. For example, Cortes and Gillam (2020) was conducted

443 over a $\sim 100 \mathrm{~km}$ of the Missouri River while our study focuses on much larger scales. It's possible

444 that the $100 \mathrm{~km}$ portion of the river studied by Cortes and Gillam (2020) is not widely used as a

445 linear feature for navigation but the use of rivers is common when looking more broadly. The

446 last possibility for the apparent tracking of rivers and coasts is that increased tree cover also

447 appears to follow these same features (i.e., near river $=$ more trees; as observed in tree cover

448 maps from Hansen et al. 2013). While there are multiple hypotheses for the tracking of linear

449 features, we are not able to distinguish between them, and it could even be some combination of

450 them all. Further, the rationale for use of linear features likely vary among and between species

451 of bats. As noted above, while all this may be true, we only present the most likely path for

452 migration but that does not mean it is the only path. While individuals likely vary, the broad

453 trends observed in our data can inform the conservation of these species.

Conservation for migratory bat species needs to be politically and geographically broad

to be effective (Fleming 2019). Conservation plans need to include protecting roost sites (during

456 all stages of life), stop-over sites, and conserving foraging habitat around these sites (Fleming

457 2019). Our results give direction as to where to look for stopover sites during migration, provide

458 a starting point to identify areas where protecting habitat for migration is needed, and supply 
459 information as to where to best implement smart-curtailment mitigation methods during fall

460 migration (Hayes et al. 2019).

461

462

463

464

465

466

467

468

469

470

471

472

473

474

475

476

477

478

479

480

481

In addition, there has been a recent focus on understanding the small-scale patterns of the movement that are embedded in larger migration patterns of these bats to develop effective conservation measures at small spatial scales (e.g., Baerwald, Patterson, \& Barclay 2014). Our results contribute to this effort by providing specific hypothesis with which to direct future studies that focus on understanding small-scale aspects of the larger migration movements. For example, researchers could look for migration through regions highlighted here by using acoustic detectors or other methods along areas of the Mississippi River or in areas moving between coastal and nearby mountain ranges, similar to the work done by Cortes and Gillam (2020) along the Missouri River. This type of research could identify areas of high bat activity during migration periods where mitigation efforts could be focused to have the largest impact through reduction of mortality due to wind farms and other causes.

\section{Conclusions}

Developing a better understanding about how these species move to and from summer habitat may be key in reducing the number of bats killed at wind farms. With bats making significant contributions to the economy of the United States through ecosystem services (Boyles et al. 2011) and provide valuable ecological services (Ghanem \& Voigt 2012) effective and practical measures are necessary to reduce the number of bat deaths annually at wind farms (Frick et al. 2017). By understanding migration, we can better mitigate and conserve species that are currently of concern in many states (e.g. Ohio Division of Wildlife 2015). Our study provides SDMs that can be used as priors in conjunction with isotopic or other biomarker models for determining movement and more importantly, establish a proof of concept of how SDMs can be 
482 used to predict migratory pathways. We further provide more information on the movements of 483 migratory bats, thereby informing researchers on where to focus our efforts towards the goal of 484 reducing bat mortality due to wind farms.

\section{Acknowledgements}

486 We like to thank the Carstens and Gibbs lab groups in the Department of EEOB at Ohio State for 487 their help in proofreading and editing of this manuscript. We also thank Erin Hazelton and 488 Jonathan Sorg, Ohio Division of Wildlife, for assistance with grant administration. This work 489 was supported by a grant (GRT00046616) from the Competitive State Wildlife Grants Program 490 to Ohio State University and the University of Maryland Center for Environmental Science as 491 jointly administered by the US Fish and Wildlife Service, the Ohio Division of Wildlife and the

492 Maryland Division of Natural Resources. This study is a contribution from the Ohio Biodiversity 493 Conservation Partnership between Ohio State University and the Ohio Division of Wildlife. 
495

496

497

498

499

500

501

502

503

504

505

506

507

508

509

510

511

512

513

514

515

516

517

\section{References}

Ahlén, I., Baagøe, H. J., \& Bach, L. (2009). Behavior of Scandinavian bats during migration and foraging at sea. Journal of Mammalogy, 90(6), 1318-1323.

Åkesson, S., Klaassen, R., Holmgren, J., Fox, J. W., \& Hedenström, A. (2012). Migration routes and strategies in a highly aerial migrant, the common swift Apus apus, revealed by lightlevel geolocators. PLoS ONE, 7.

Araújo, M. B., \& New, M. (2007). Ensemble forecasting of species distributions. Trends in Ecology \& Evolution, 22, 42-47.

Arnett, E. B., \& Baerwald, E. F. (2013). Impacts of wind energy development on bats: implications for conservation. In R. Adams \& S. Pederson (Eds.), Bat Evolution, Ecology, and Conservation (pp. 435-456). New York: Springer.

Arnett, E. B., Brown, W. K., Erickson, W. P., Fielder, J. K., Hamilton, B. L., Henry, T. H., ... Tankersley, R. D. (2008). Patterns of Bat Fatalities at Wind Energy Facilities in North America. Journal of Wildlife Management, 72(1), 61-78. https://doi.org/10.2193/2007-221

Baerwald, E. F., \& Barclay, R. M. (2011). Patterns of activity and fatality of migratory bats at a wind energy facility in Alberta, Canada. The Journal of Wildlife Management, 75, 11031114.

Baerwald, E. F., Patterson, W. P., \& Barclay, R. M. R. (2014). Origins and migratory patterns of bats killed by wind turbines in southern Alberta: evidence from stable isotopes. Ecosphere, $5,1-17$.

Baerwald, E. F., Weller, T. J., Green, D. M., \& Holland, R. A. (2021). There and Back Again: Homing in Bats Revisited. In B.K. Lim et al. (Eds), 50 Years of Bat Research (pp. 173187). Switzerland, Springer. 
518 Baloun, D. E., \& Guglielmo, C. G. (2019). Energetics of migratory bats during stopover: a test of

519 the torpor-assisted migration hypothesis. Journal of Experimental Biology, 222, 885-893.

520 Barnhart, P. R., \& Gillam, E. H. (2017). Documentation of overwintering bat species presence

521 and hibernacula use in the badlands of North Dakota. Northwestern Naturalist 48-56.

522 Bivand, R., Lewin-Koh, N., Pebesma, E., Archer, E., Baddeley, A., Bearman, N., ... Dray, S.

523 (2019). Package 'maptools.' R package.

524 Bond, M. L., Bradley, C. M., Kiffner, C., Morrison, T. A., \& Lee, D. E. (2017). A multi-method

525 approach to delineate and validate migratory corridors. Landscape Ecology, 32, 1705-1721.

526 Booth, T. H., Nix, H. A., Busby, J. R., \& Hutchinson, M. F. (2014). BIOCLIM: the first species

527 distribution modelling package, its early applications and relevance to most current

528 MAXENT studies. Diversity and Distributions, 20(1), 1-9.

529 Boyles, J. G., Cryan, P. M., McCracken, G. F., \& Kunz, T. H. (2011). Economic importance of 530 bats in agriculture. Science, 332, 41-42.

531 Breiman, L. (2001). Random forests. Machine learning, 45(1), 5-32.

532 Burke, R. A., Frey, J. K., Ganguli, A., \& Stoner, K. E. (2019). Species distribution modelling

533 supports "nectar corridor" hypothesis for migratory nectarivorous bats and conservation of $534 \quad$ tropical dry forest. Diversity and Distributions, 25, 1-17.

535 Carstens, B. C., Morales, A. E., Field, K., \& Pelletier, T. A. (2018). A global analysis of bats 536 using automated comparative phylogeography uncovers a surprising impact of Pleistocene 537 glaciation. Journal of Biogeography, 45, 1795-1805.

538 Cortes, K. M., \& Gillam, E. H. (2020). Assessing the use of rivers as migratory corridors for 539 temperate bats. Journal of Mammalogy, 101, 448-454. 
540 Cryan, P. M. (2003). Seasonal Distributions of Migratory Tree Bats (Lasiurus and Lasionycteris)

541 in North America. Journal of Mammalogy, 84, 579-593.

542 Cryan, P. M., Stricker, C. A., \& Wunder, M. B. (2014). Continental-scale, seasonal movements

543 of a heterothermic migratory tree bat. Ecological Applications, 24(4), 602-616.

544 Di Cola, V., Broennimann, O., Petitpierre, B., Breiner, F. T., D’Amen, M., Randin, C., ...

545 Pellissier, L. (2017). ecospat: an R package to support spatial analyses and modeling of $546 \quad$ species niches and distributions. Ecography, 40, 774-787.

547 Didan, K., Munoz, A. B., Solano, R., \& Huete, A. (2015, June). MODIS Vegetation Index User's 548 Guide (MOD 13 Series) version 3, June 2015 (Collection 6).

549 Dutta, T., Sharma, S., McRae, B. H., Roy, P. S., \& DeFries, R. (2016). Connecting the dots:

550 mapping habitat connectivity for tigers in central India. Regional Environmental Change, $551 \quad 16(1), 53-67$.

552 Falxa, G. (2007). Winter foraging of silver-haired and California myotis bats in western

553 Washington. Northwestern Naturalist 88(2):98-100.

554 Feeley, K. J., \& Silman, M. R. (2011). Keep Collecting: accurate species distribution modelling 555 requires more collections than previously thought. Diversity and Distributions, 17, 11325561140.

557 Feng, X., Park, D. S., Walker, C., Peterson, A. T., Merow, C., \& Papeş, M. (2019). A checklist 558 for maximizing reproducibility of ecological niche models. Nature Ecology \& Evolution, 3, $559 \quad 1382-1395$.

560 Fick, S. E., \& Hijmans, R. J. (2017). WorldClim 2: new 1-km spatial resolution climate surfaces 561 for global land areas. International Journal of Climatology, 37, 4302-4315. 
562 Findley, J. S., \& Jones, C. (1964). Seasonal Distribution of the Hoary Bat. Journal of 563 Mammalogy, 45, 461-470.

564 Fink, D., Hochachka, W. M., Zuckerberg, B., Winkler, D. W., Shaby, B., Munson, M. A., ...

565 Kelling, S. (2010). Spatiotemporal exploratory models for broad-scale survey data.

566 Ecological Applications, 20, 2131-2147.

567 Fleming, T. H. (2019). Bat Migration. In Encyclopedia of Animal Behavior (pp. 605-610).

$568 \quad$ PMCID: PMC7149675.

569 Fleming, T. H., \& Eby, P. (2003). Ecology of bat migration. In T. H. Kunz \& M. B. Fenton

570 (Eds.), Bat Ecology (pp. 164-208). The University of Chicago Press.

571 Fourcade, Y., Engler, J. O., Rödder, D., \& Secondi, J. (2014). Mapping species distributions with

572 MAXENT using a geographically biased sample of presence data: a performance

573 assessment of methods for correcting sampling bias. PloS one, 9(5), e97122.

574 Frick, W. F., Baerwald, E. F., Pollock, J. F., Barclay, R. M. R., Szymanski, J. A., Weller, T. J., $575 \quad$... McGuire, L. P. (2017). Fatalities at wind turbines may threaten population viability of a 576 migratory bat. Biological Conservation, 209, 172-177.

577 Furmankiewicz, J., \& Kucharska, M. (2009). Migration of bats along a large river valley in 578 southwestern Poland. Journal of Mammalogy, 90, 1310-1317.

579 Geary, R. C. (1954). The contiguity ratio and statistical mapping. The Incorporated Statistician, $580 \quad 5,115-146$.

581 Ghanem, S. J., \& Voigt, C. C. (2012). Increasing Awareness of Ecosystem Services Provided by 582 Bats. In H. J. Brockmann, J. Roper, Timothy, M. Naguib, J. C. Mitani, \& L. W. Simmons 583 (Eds.), Advances in the Study of Behavior (44th ed., pp. 279-302). Academic Press. 
584 Giavi, S., Moretti, M., Bontadina, F., Zambelli, N., \& Schaub, M. (2014). Seasonal survival 585 probabilities suggest low migration mortality in migrating bats. PLoS ONE, 9(1), e85628. $586 \quad$ https://doi.org/10.1371/journal.pone.0085628

587 Guisan, A., Edwards Jr, T. C., \& Hastie, T. (2002). Generalized linear and generalized additive 588 models in studies of species distributions: setting the scene. Ecological modelling, 157(2-3), $589 \quad 89-100$.

590 Hansen, M. C., Potapov, P. V, Moore, R., Hancher, M., Turubanova, S. A., Tyukavina, A., ... 591 Kommareddy, A. (2013). High-resolution global maps of 21st-century forest cover change. $592 \quad$ Science, 342, 850-853.

593 Hatch, S. K., Connelly, E. E., Divoll, T. J., Stenhouse, I. J., \& Williams, K. A. (2013). Offshore 594 observations of eastern red bats (Lasiurus borealis) in the mid-Atlantic United States using 595 multiple survey methods. PloS one, 8(12), e83803.

596 Hayes, M. A., Cryan, P. M., \& Wunder, M. B. (2015). Seasonally-dynamic presence-only 597 species distribution models for a cryptic migratory bat impacted by wind energy $598 \quad$ development. PLoS ONE, 10, e0132599.

599 Hayes, M. A., Hooton, L. A., Gilland, K. L., Grandgent, C., Smith, R. L., Lindsay, S. R., ... 600 Goodrich-Mahoney, J. (2019). A smart curtailment approach for reducing bat fatalities and 601 curtailment time at wind energy facilities. Ecological Applications, 29, e01881.

602 Hijmans, R. J., \& Elith, J. (2017). Species distribution modeling with R Introduction. R Cran 603 Project.

604 Hijmans, R. J., Phillips, S., Leathwick, J., Elith, J., \& Hijmans, M. R. J. (2017). Package ‘dismo’, $605 \quad$ R Package. R package. 
606 Hijmans, R. J., Van Etten, J., Cheng, J., Mattiuzzi, M., Sumner, M., Greenberg, J. A., ...

607 Hijmans, M. R. J. (2019). Package “raster”, R Package. Package 'raster.'

608 Hobson, K. A., \& Wassenaar, L. I. (2018). Tracking Animal Migration with Stable Isotopes (2nd 609 ed.). Academic Press.

610 Howey, M. C. L. (2011). Multiple pathways across past landscapes: circuit theory as a 611 complementary geospatial method to least cost path for modeling past movement. Journal 612 of Archaeological Science, 38, 2523-2535.

613 Ijäs, A., Kahilainen, A., Vasko, V. V, \& Lilley, T. M. (2017). Evidence of the migratory bat, 614 Pipistrellus nathusii aggregating to the coastlines in the Northern Baltic Sea. Acta $615 \quad$ Chiropterologica, 19, 127-139.

616 Johnson, J. S., Watrous, K. S., Giumarro, G. J., Peterson, T. S., Boyden, S. A., \& Lacki, M. J. 617 (2011). Seasonal and geographic trends in acoustic detection of tree-roosting bats. Acta $618 \quad$ Chiropterologica, 13, 157-168.

619 Jung, K., \& Threlfall, C. G. (2018). Trait-dependent tolerance of bats to urbanization: a global 620 meta-analysis. Proceedings of the Royal Society B: Biological Sciences, 285, 20181222.

621 Kramer-Schadt, S., Niedballa, J., Pilgrim, J. D., Schröder, B., Lindenborn, J., Reinfelder, V., ... 622 \& Wilting, A. (2013). The importance of correcting for sampling bias in MaxEnt species 623 distribution models. Diversity and Distributions, 19(11), 1366-1379.

624 Krauel, J. J., McGuire, L. P., \& Boyles, J. G. (2018). Testing traditional assumptions about 625 regional migration in bats. Mammal Research, 63, 115-123.

626 Kuhn, M., Wing, J., Weston, S., Williams, A., Keefer, C., Engelhardt, A., ... Benesty, M. (2020). 627 Package “caret”, R Package. Package 'caret.' 
628 Kunz, T. H., Arnett, E. B., Erickson, W. P., Hoar, A. R., Johnson, G. D., Larkin, R. P., ... Tuttle, 629 M. D. (2007). Ecological impacts of wind energy development on bats: questions, research 630 needs, and hypotheses. Frontiers in Ecology and the Environment, 5, 315-324.

631 Lacoeuilhe, A., Machon, N., Bocq, A. Le, \& Kerbiriou, C. (2014). The influence of low 632 intensities of light pollution on bat communities in a semi-natural context. PLoS ONE.

633 Lehnert, L. S., Kramer-schadt, S., Teige, T., Hoffmeister, U., Popa-lisseanu, A., Bontadina, F., 634 ... Voigt, C. C. (2018). Variability and repeatability of noctule bat migration in Central 635 Europe : evidence for partial and differential migration. Proceedings of the Royal Society B: 636 Biological Sciences, 285, 20182174.

637 Liaw, A., \& Wiener, M. (2018). Package 'randomForest', R Package.'

638 Lincoln, F. C. (1935). The waterfowl flyways of North America (No 342). US Department of 639 Agriculture.

640 MacLeod, C. D. (2009). Global climate change, range changes and potential implications for the 641 conservation of marine cetaceans: a review and synthesis. Endangered Species Research, $642 \quad 7(2), 125-136$.

643 Marmion, M., Parviainen, M., Luoto, M., Heikkinen, R. K., \& Thuiller, W. (2009). Evaluation of 644 consensus methods in predictive species distribution modelling. Diversity and Distributions, $645 \quad 15,59-69$.

646 Marrotte, R. R., \& Bowman, J. (2017). The relationship between least-cost and resistance 647 distance. PLoS ONE, 12, 1-19.

648 Mateo, G., Vanderpoorten, A., Munoz, J., Laenen, B., \& Desamore, A. (2013). Modeling species 649 distributions from heterogeneous data for the biogeographic regionalization of the European $650 \quad$ bryophyte flora. PLoS ONE, 8, e55648. 
651 McClure, M. L., Hansen, A. J., \& Inman, R. M. (2016). Connecting models to movements:

652 testing connectivity model predictions against empirical migration and dispersal data. $653 \quad$ Landscape Ecology, 31, 1419-1432.

654 McGuire, L. P. (2019). Migratory wanderings: bat migration at the regional scale. Bat Research $655 \quad$ News, 60(1): 46-47.

656 McRae, B. H., \& Beier, P. (2007). Circuit theory predicts gene flow in plant and animal 657 populations. Proceedings of the National Academy of Sciences, 104, 19885-19890.

658 Medley, K. A., Jenkins, D. G., \& Hoffman, E. A. (2015). Human-aided and natural dispersal 659 drive gene flow across the range of an invasive mosquito. Molecular Ecology, 24(2), 284660295.

661 Mi, C., Huettmann, F., Guo, Y., Han, X., \& Wen, L. (2017). Why choose Random Forest to 662 predict rare species distribution with few samples in large undersampled areas? Three Asian 663 crane species models provide supporting evidence. PeerJ, 5, e2849.

664 Monopoli, M., Wieringa, J. G., Nagel, J., Nelson, D. M., \& Gibbs, H. L. (2020). Sequencing 665 whole mitochondrial genomes to assess genetic divergence between proposed silver-haired 666 bat (Lasionycteris noctivagans) populations. Mitochondrial DNA Part B, 5(4), 3838-3839.

667 Moran, P. A. (1950). Notes on continuous stochastic phenomena. Biometrika, 37, 17-23.

668 Morningstar, D., \& Sandilands, A. (2019). Summer movements of a radio-tagged Hoary Bat 669 (Lasiurus cinereus) captured in southwestern Ontario. The Canadian Field-Naturalist, $670 \quad 133(2), 125-129$.

671 Muscarella, R., Galante, P. J., Soley-guardia, M., Boria, R. A., Kass, J. M., \& Anderson, R. P. 672 (2014). ENMeval: An R package for conducting spatially independent evaluations and 
673

674

675

676

677

678

679

680

681

682

683

684

685

686

687

688

689

690

691

692

693

694

695 estimating optimal model complexity for MAXENT ecological niche models. Methods in Ecology and Evolution, 5, 1198-1205.

Muthersbaugh, M. S., Ford, W. M., Powers, K. E., \& Silvis, A. (2019). Activity Patterns of Bats During the Fall and Spring Along Ridgelines in the Central Appalachians. Journal of Fish and Wildlife Management, 10(1), 180-195.

National Audubon Society. (2010). The Christmas Bird Count Historical Results. Retrieved from Www.christmasbirdcount.org

Ohio Department of Natural Resources, Division of Wildlife. (2015). Ohio's State Wildlife Action Plan. Columbus, OH, USA.

Pebesma, E., Bivand, R., \& Pebesma, M. E. (2012). Package ‘sp', R Package.

Pettit, J. L., \& O’Keefe, J. M. (2017). Day of year, temperature, wind, and precipitation predict timing of bat migration. Journal of Mammalogy, 98, 1236-1248.

Phillips, S. J., Dudik, M., \& Schapire, R. E. (2017). Maxent software for modeling species niches and distributions (Version 3.4.1).

Poor, E. E., Loucks, C., Jakes, A., \& Urban, D. L. (2012). Comparing habitat suitability and connectivity modeling methods for conserving pronghorn migrations. PLoS ONE, 7, e49390.

Razgour, O., Rebelo, H., Febbraro, D., M., \& Russo, D. (2016). Painting maps with bats: species distribution modelling in bat research and conservation. Hystrix: The Italian Journal of Mammalogy, 27, 1-8.

Reimer, J. P., Baerwald, E. F., \& Barclay, R. M. (2018). Echolocation activity of migratory bats at a wind energy facility: testing the feeding-attraction hypothesis to explain fatalities. Journal of Mammalogy, 99, 1472-1477. 
696 Reynolds, M. D., Sullivan, B. L., Hallstein, E., Matsumoto, S., Kelling, S., Merrifield, M., ...

697 Morrison, S. A. (2017). Dynamic conservation for migratory species. Science Advances, $698 \quad 3(8), \mathrm{e} 1700707$.

699 Rydell, J., Bach, L., Dubourg-Savage, M. J., Green, M., Rodrigues, L., \& Hedenström, A. 700 (2010). Mortality of bats at wind turbines links to nocturnal insect migration? European $701 \quad$ Journal of Wildlife Research, 56, 823-827.

702 Shah, V. B., \& McRae, B. (2008). Circuitscape: A tool for landscape ecology. Proceedings of the 703 7th Python in Science Conference, SciPy, 62-65.

704 Shaw, A. K., \& Couzin, I. D. (2013). Migration or residency? The evolution of movement 705 behavior and information usage in seasonal environments. The American Naturalist, 181, $706 \quad 114-124$.

707 Simmons, N. B., \& Cirranello, A. L. (2020). Bat species of the world: a taxonomic and 708 geographic database. Retrieved from batnames.org

709 Sjollema, A. L., Gates, J. E., Hilderbrand, R. H., \& Sherwell, J. (2014). Offshore activity of bats 710 along the Mid-Atlantic Coast. Northeastern naturalist, 21(2), 154-163.

711 Smeraldo, S., Di Febbraro, M., Bosso, L., Flaquer, C., Guixé, D., Lisón, F., ... Russo, D. (2018).

712 Ignoring seasonal changes in the ecological niche of non-migratory species may lead to 713 biases in potential distribution models: lessons from bats. Biodiversity and Conservation, $714 \quad 27,2425-2441$.

715 Sullivan, B. L., Wood, C. L., Iliff, M. J., Bonney, R. E., Fink, D., \& Kelling, S. (2009). eBird: a 716 citizen-based bird observation network in the biological sciences. Biological Conservation, 717 $142,2282-2292$. 
718 Tachikawa, T., Kaku, M., Iwasaki, A., Gesch, D. B., Oimoen, M. J., Zhang, Z., ... Abrams, M. 719 (2011). ASTER global digital elevation model version 2-summary of validation results.

720 Tracy, J. L., Kantola, T., Baum, K. A., \& Coulson, R. N. (2019). Modeling fall migration 721 pathways and spatially identifying potential migratory hazards for the eastern monarch 722 butterfly. Landscape Ecology, 34, 443-458.

723 Urbanek, S. (2019). Package 'rJava', R Package.

724 van Etten, \& J. (2017). R Package gdistance: Distances and Routes on Geographical Grids.

$725 \quad$ Journal of Sta, 76.

726 van Proosdij, J., A. S., Sosef, M. S. M., Wieringa, J. J., \& Raes, N. (2016). Minimum required 727 number of specimen records to develop accurate species distribution models. Ecography, $728 \quad 39,542-552$.

729 Voigt, C. C., Frick, W. F., Holderied, M. W., Holland, R., Kerth, G., Mello, M. A. R., ... Yovel, 730 Y. (2017). Principles and patterns of bat movements: from aerodynamics to ecology. The 731 Quarterly Review of Biology, 92, 267-287.

732 Voigt, C. C., Lindecke, O., Schonborn, S., Kramer-Schadt, S., \& Lehmann, D. (2016). Habitat 733 use of migratory bats killed during autumn at wind turbines. Ecological Applications, 26(3), 734 $771-783$.

Wang, Y., Pan, Y., Parsons, S., Walker, M., \& Zhang, S. (2007). Bats respond to polarity of a 736 magnetic field. Proceedings of the Royal Society B: Biological Sciences, 274, 2901-2905.

Webster, M. S., Marra, P. P., Haig, S. M., Bensch, S., \& Holmes, R. T. (2002). Links between 738 worlds: unraveling migratory connectivity. Trends in Ecology \& Evolution, 17, 76-83. 
739 Welbergen, J. A., Meade, J., Field, H. E., Edson, D., McMichael, L., Shoo, L. P., ... Martin, J.

740 M. (2020). Extreme mobility of the world's largest flying mammals creates key challenges

741 for management and conservation. BMC Biology, 18, 1-13.

742 Weller, T. J., Castle, K. T., Liechti, F., Hein, C. D., Schirmacher, M. R., \& Cryan, P. M. (2016).

743 First direct evidence of long-distance seasonal movements and hibernation in a migratory

$744 \quad$ bat. Scientific Reports, 6, 1-7.

745 Westbrook, J. K., Nagoshi, R. N., Meagher, R. L., Fleischer, S. J., \& Jairam, S. (2016). Modeling

746 seasonal migration of fall armyworm moths. International Journal of Biometeorology, 60,

$747 \quad 255-267$.

748 Wildlife Conservation Society - WCS, and Center for International Earth Science Information

749 Network - CIESIN - Columbia University. (2005). Last of the Wild Project, Version 2, 2005

750 (LWP-2): Global Human Influence Index (HII) Dataset (Geographic). Palisades, NY:

751 NASA Socioeconomic Data and Applications Center (SEDAC)

752 


\section{Table $\mathbf{1}$ (on next page)}

\section{GBIF Occurrence Data}

Number of GBIF occurrence points per month for each species analyzed after filtering 


\begin{tabular}{|c|c|c|c|c|c|c|c|c|c|c|c|c|}
\hline & January & February & March & April & May & June & Mly & August & September & October & November & December \\
\hline L. borealis & 45 & 33 & 44 & 75 & 99 & 151 & 205 & 192 & 123 & 86 & 49 & 27 \\
\hline L. ineress & 29 & 38 & 44 & 80 & 99 & 108 & 125 & 138 & 110 & 86 & 36 & 24 \\
\hline L. notivagans & 25 & 24 & 28 & 62 & 110 & 111 & 104 & 131 & 106 & 74 & 38 & 21 \\
\hline Totd & 99 & 95 & 116 & 217 & 308 & 370 & 434 & 461 & 339 & 246 & 123 & 72 \\
\hline
\end{tabular}




\section{Table 2 (on next page)}

Variable Importance

Variable importance rank for three of the four SDM models implemented in these analyses. 1

- indicates the most important variable, while 9 - represents the least important. Each importance was found by the following: RF we used the 'importance' function in the "randomForest" R package, MaxEnt, variable importance was assessed using 'var.importance' function in "ENMeval", GLM model, we used the 'varlmp' function present in "caret". 
Precipitation Solar Radiation Temperature Vapor Pressure Wind Speed Human Influence Elevation NDVI Forest Cover

Random Forest

MaxENT

GLM

5

5
6

6

3

3

3

3

8

8

8
7

7

4

4
4

4

5

5

5
5

$\begin{array}{ll}6 & 9 \\ 7 & 9 \\ 8 & 9\end{array}$




\section{Table 3 (on next page)}

Spatial Clustering of Paths

Moran's I and Geary's C to determine if clustering among potential migratory pathways is present. For Moran's I, values range between -1 and 1, with values above 1 indicating positive clustering. Geary's $C$ values range between 0 and 2, with values below 1 indicating positive clustering. Results given for paired t-tests comparing Euclidean and Least-Cost distances. 


\begin{tabular}{|c|c|c|c|c|c|c|c|c|c|c|c|c|}
\hline & \multicolumn{6}{|c|}{ Spring } & \multicolumn{6}{|c|}{ Fall } \\
\hline & \multicolumn{2}{|c|}{ Moran's I } & \multicolumn{2}{|c|}{ Geary's C } & \multicolumn{2}{|c|}{ Paired t-test } & \multicolumn{2}{|c|}{ Moran's I } & \multicolumn{2}{|c|}{ Geary's C } & \multicolumn{2}{|c|}{ Paired t-test } \\
\hline & $\mathrm{I}$ & $\mathrm{p}$-value & $\mathrm{C}$ & p-value & Mean Increase & p-value & 1 & p-value & $\mathrm{C}$ & p-value & Mean Increase & p-value \\
\hline L. nodivagans & 0.39 & 0.01 & 0.60 & 0.01 & 880.40 & $<<0.001$ & 0.34 & 0.01 & 0.67 & 0.01 & 767.16 & $<0.001$ \\
\hline L. boredis & 0.45 & 0.01 & 0.54 & 0.01 & 348.33 & $<0.001$ & 0.42 & 0.01 & 0.56 & 0.01 & 325.39 & $<0.001$ \\
\hline L. aneress & 0.36 & 0.01 & 0.65 & 0.01 & 721.51 & $<0.001$ & 0.37 & 0.01 & 0.63 & 0.01 & 526.85 & $<0.001$ \\
\hline
\end{tabular}


Figure 1

\section{Methods Overview}

Flowchart showing how occurrence data were analyzed and used to infer migratory pathways for each bat species. 


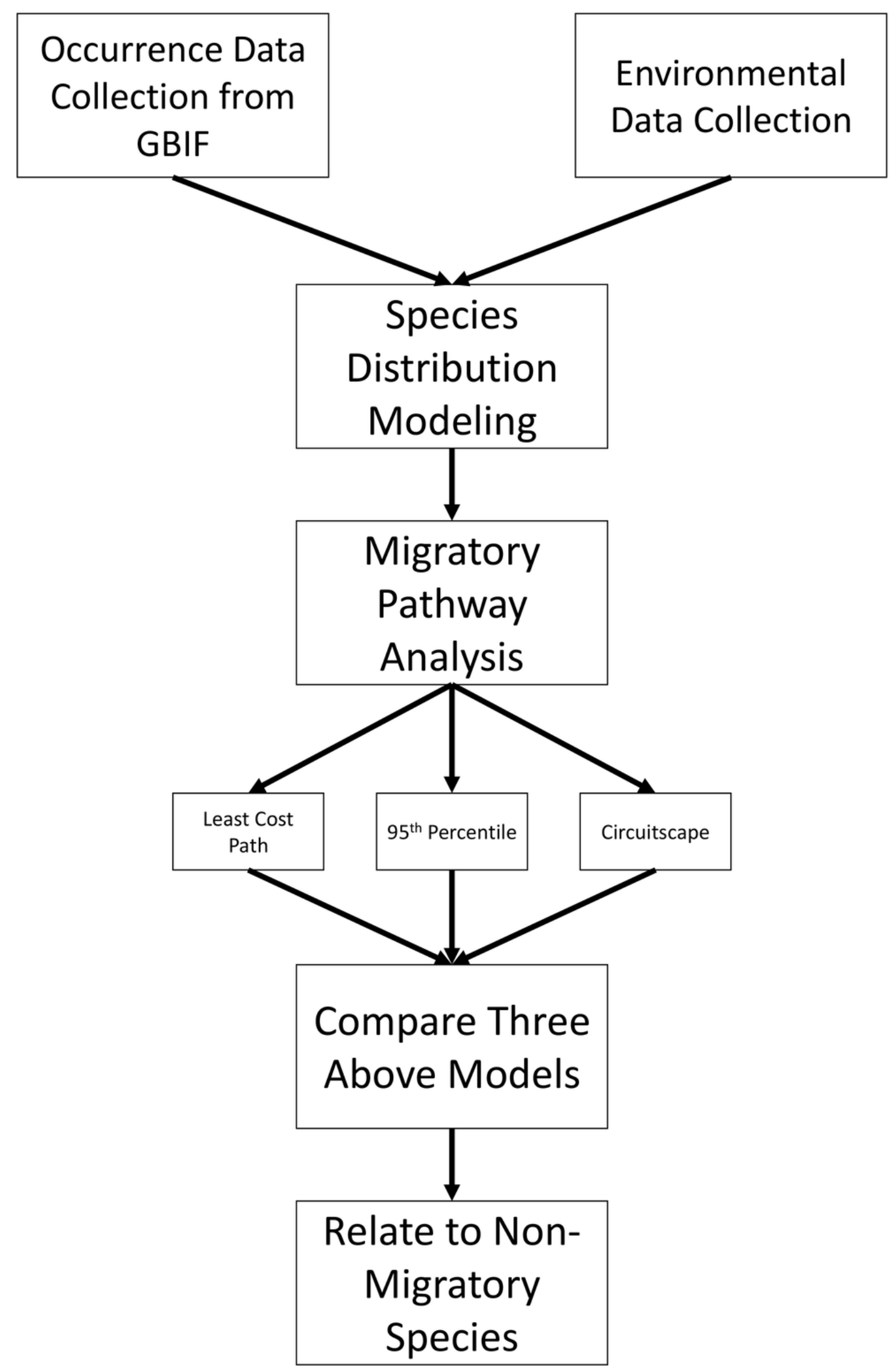


Figure 2

Occurrences Used for Species Distribution Models

Each dot indicates a filtered occurrence for a migratory species. Each of these points are then given a color based on the month when the occurrence was detected. These points were then used in order to generate species distribution models for each season of a species.

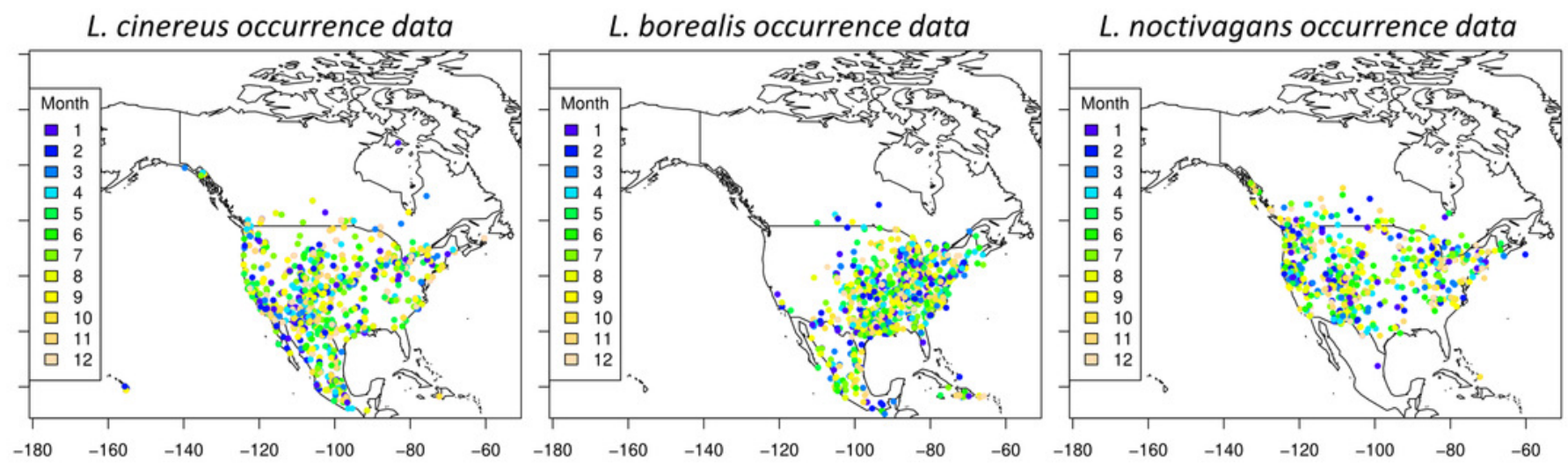




\section{Figure 3}

Seasonal Suitability for Three Species of Migratory Bat Species

Seasonal SDMs for all three species (L. borealis, L. cinereus, and L. noctivagans). Colors identify either individual species or groups of species that occur in a given area. Outlier cells have been removed, and all rasters rescaled to range from 0 to 1 . For more detailed figures for each species, see supplemental Figures S2-S4.
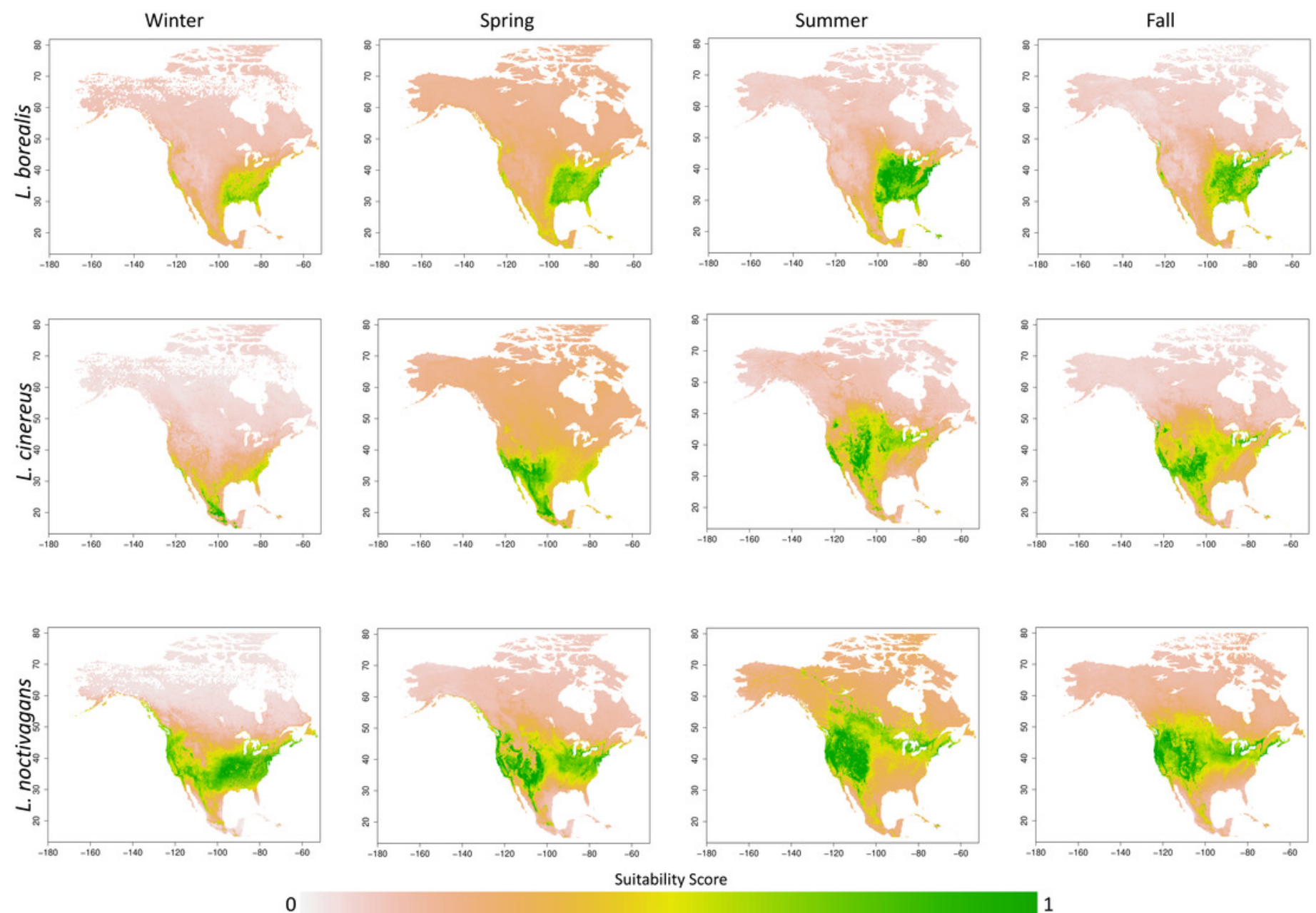


\section{Figure 4}

\section{Potential Migratory Pathways}

Migration pathways determined using two approaches: binary models determined from TSS weighted ensemble model using $95^{\text {th }}$ percentile threshold determined for each species (shown in grey and white), and least-cost-path density (shown as color gradient) for $L$. borealis, L. cinereus, and L. noctivagans, M. lucifugus, and E. fuscus.
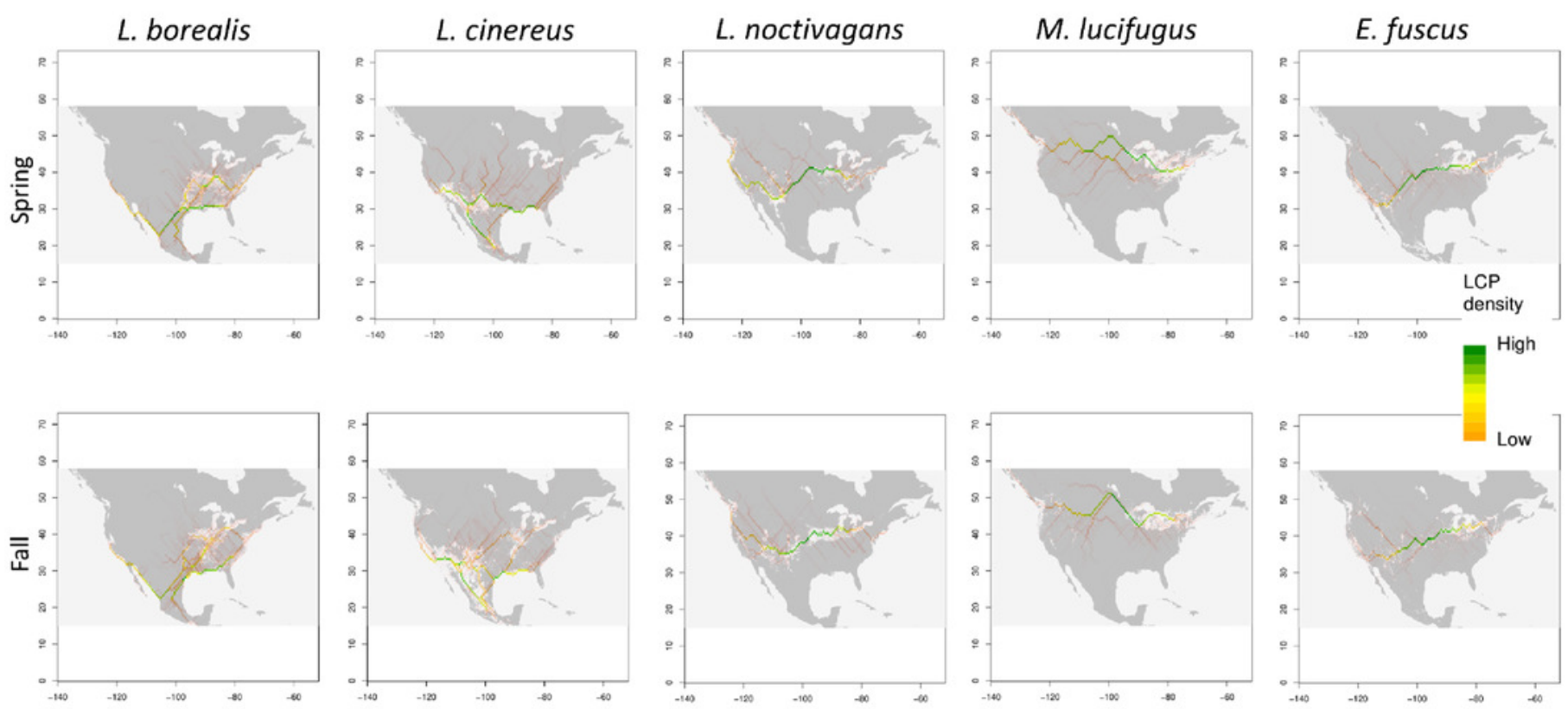